\title{
Intramuscular Transplantation of Allogeneic Mesenchymal Stromal Cells Derived from Equine Umbilical Cord
}

\author{
Marianne Camargos Dias ${ }^{1}$, Fernanda da Cruz Landim-Alvarenga ${ }^{1}$, \\ Carolina Nogueira de Moraes ${ }^{1}$, Leonardo Dourado da Costa ${ }^{2}$, Caroline Medeiros Geraldini ${ }^{1}$, \\ Vânia Maria de Vasconcelos Machado ${ }^{1}$, Leandro Maia ${ }^{1}$ \\ Departments of ${ }^{1}$ Animal Reproduction and Veterinary Radiology, ${ }^{2}$ Veterinary Pathology, \\ College of Veterinary Medicine and Animal Science, São Paulo State University, UNESP, Botucatu, SP, Brazil
}

Background and Objectives: Mesenchymal stromal cells (MSCs) have great therapeutic potential, particularly in the process of tissue repair and immunomodulation through the secretion of biomolecules. Thus, the aim of this study was to evaluate the hypothesis that intramuscular transplantation of allogeneic MSCs obtained from equine umbilical cord (UC-MSCs) is safe, demonstrating that this is a suitable source of stem cells for therapeutic use.

Methods and Results: For this, UC-MSCs were cultured, characterized and cryopreserved for future transplantation in six healthy mares. On day 0, transplantation of three million UC-MSCs diluted in Hank's Balanced Solution (HBSS) was performed on right and left sides of the rump muscle. As a control, HBSS injections were performed caudally in the same muscle. Muscle biopsies were obtained as a control 30 days before transplantation (D-30). The biopsies were collected again on day 2 (left side) and day 7 (right side) post transplantation and examined histologically. All procedures were preceded by ultrasound examination and blood sampling. Hematologic evaluation remained within normal limits and no differences were observed between time points $(\mathrm{p}>0.05)$. Ultrasound examination was suggestive of inflammation 48 hours after transplantation in both groups (control and treated). At histological evaluation it was found only discrete inflammation signals between D-30 $\times \mathrm{D} 2(\mathrm{p}<0.05)$ in the treated group, without differences $(\mathrm{p}>$ 0.05 ) between the groups at different time points.

Conclusions: Equine UC-MSCs under the experimental conditions did not promote severe inflammation that causes tissue damage or lead to its rejection by the host organism and therefore has a good potential for clinical use.

Keywords: Mesenchymal stromal cells, Allogeneic, Transplantation, Muscle, Umbilical cord

Accepted for publication April 29, 2016, Published online November 30, 2016

Correspondence to Leandro Maia

Department of Animal Reproduction and Veterinary Radiology, College of Veterinary Medicine and Animal Science,

São Paulo State University, UNESP Campus Botucatu, 18618-681 Botucatu, SP, Brazil

Tel: +55(14) 3380-2119, Fax: +55(14) 3380-2119

E-mail: leandromvet@hotmail.com

(a) This is an open-access article distributed under the terms of the Creative Commons Attribution Non-Commercial License (http://creativecommons.org/ licenses/by-nc/4.0/), which permits unrestricted non-commercial use, distribution, and reproduction in any medium, provided the original work is properly cited.

\section{Introduction}

Currently there are many studies to evaluate the therapy with MSCs throughout the world. The growing interest in therapy with these cells is due their role in tissue repair and host immunomodulation without causing immune responses of alloreactive $\mathrm{T}$ cells or other effector cells (1). One of the main MSC sources of collection in equine clinical practice is the bone marrow (BM). MSCs derived from bone marrow (BM-MSCs) are usually autologous and for this, the animal is subjected to BM aspiration, which is invasive, painful and uncomfortable to the 
animal (2). In addition, BM-MSCs takes about four weeks to be expanded, which makes impossible the treatment of acute diseases in the original peak of inflammation and makes treatment costly (3). MSCs derived from fetal membranes overcome the disadvantages of other sources. Being a non-invasive source of MSCs, fetal membranes are most suitable for the creation of banks, allowing its standardization and providing MSCs immediately to therapeutic use (4).

Research suggests that equine MSCs derived from fetal membranes, includind the umbilical cord (UC) do not induce cellular inflammatory response when administered intradermal and intraarticular $(5,6)$. Most therapies use autologous MSCs, but due to its immunomodulatory capacity, it seems perfectly feasible using allogeneic MSCs (7). The stem cell therapies must be safe, which means that besides not causing rejection in the host, should not cause tumors and should be readily harvested and expanded (8). Several researches have been testing the immunogenicity of MSCs in horses and showing their safety in autologous and allogeneic transplants such as intradermal (5), intra-articular (9), intrathecal (10) and intralesional in tendon using $\mathrm{BM}$ and amniotic membrane cells (11). Additionally, equine is a good experimental model for extrapolating results to human medicine once it has several similarities to humans when referring to musculoskeletal diseases (12). Thus, this study tests the hypothesis that the intramuscular transplantation of UC-MSCs is safe for the equine experimental model with the possibility of extrapolating the results and benefits to other species, including human.

\section{Materials and Methods}

The experimental protocol (145/2013-CEUA) was approved by the ethics and welfare committee of the São Paulo State University - Botucatu.

\section{Selection and management of animals for in vivo experimentation}

Six healthy mixed breed mares, aged 6 to 12 years and weighting between 300 and $500 \mathrm{~kg}$ were selected for the transplantation of UC-MSCs. The animals were selected by physical, hematological and ultrasound of superficial gluteal muscle evaluations prior the experimental period, and those with no alteration on the exams were used.

\section{Collection of umbilical Cord (UC)}

Equine UC sample were collected at a Thoroughbred farm. For this, a segment of UC of approximately $10 \mathrm{~cm}$ was collected and washed with phosphate buffer saline (PBS), pH 7.4 containing antibiotics (1\%) and antimycotic $(1.2 \%)$. After, the sample was conditioned into a $50 \mathrm{ml}$ tube containing medium composed by Dulbecco's Modified Eagle's Medium (DMEM) high glucose, 20\% fetal bovine serum (FBS), penicillin (100 IU/ml), streptomycin (100 $\mathrm{mg} / \mathrm{ml}$ ) and amphotericin (3 $\mu \mathrm{g} / \mathrm{ml})$ (Gibco, USA), stored and transported at $5^{\circ} \mathrm{C}$ in a refrigerated transport system (Botutainer ${ }^{\circledR}$, Botupharma, Brazil).

\section{Isolation and culture of UC-MSCs}

At the laboratory, the intervascular segment of UC was washed in PBS with penicillin/streptomycin (1\%), dissected for total removal of the blood vessel and fragmented to facilitate enzymatic digestion with collagenase solution $(1 \mathrm{mg} / \mathrm{ml})$ (Sigma, USA) at $37^{\circ} \mathrm{C}$. After the digestion, the sample was filtered through $70 \mu \mathrm{m}$ filters (BD Bioscienses, USA) and subsequently centrifuged with DMEM high glucose at $350 \mathrm{~g}$ for 10 minutes. Then the supernatant was discarded and the pellet resuspended and cultured on maintenance medium composed by DMEM high glucose, $20 \% \mathrm{FBS}$, penicillin $(100 \mathrm{IU} / \mathrm{ml})$, streptomycin $(100 \mathrm{mg} / \mathrm{ml})$, amphotericin $(3 \mu \mathrm{g} / \mathrm{ml})$ and amikacin $(11 \mu \mathrm{g} / \mathrm{ml})$ at $37.5^{\circ} \mathrm{C}$ in a humidified atmosphere containing $5 \% \mathrm{CO}_{2}$ in air.

UC-MSCs in second passage were washed and resuspended slowly with cryopreservation medium $(90 \%$ FBS, 10\% dimethyl sulfoxide (DMSO) (Sigma-Aldrich Corp., USA), penicillin/streptomycin and amphotericin B) to a final concentration of $3 \times 10^{6} \mathrm{cells} / \mathrm{ml}$. The cryotubes with cell suspensions were placed in a cryogenic container (Mr. Frosty, Nalgene), which provides a gradual cooling rate of $-1^{\circ} \mathrm{C} /$ minute until $-80^{\circ} \mathrm{C}$. Passed 24 hours in a $-80^{\circ} \mathrm{C}$ freezer, the cryotubes were placed quickly in liquid nitrogen.

\section{Assays of osteogenic and adipogenic differentiation}

The assays were performed according to the methodology described by Maia et al. (13) with modifications. The osteogenic and adipogenic differentiation potential of UC-MSCs was evaluated after staining with Alizarim red on the 10th day or with Oil red on the 8th day, respectively.

\section{Flow cytometry analysis}

Immunophenotypic analysis of UC-MSCs was done in second passage (fresh) and after cryopreservation (third passage). The characterization was performed in a flow cytometer (LSRFORTESSA, BD Bioscienses, USA) using the monoclonal mouse anti-rat CD90 (abDSerotec, USA), mouse anti-human CD34 (Becton Dickinson and Company, USA), mouse anti-horse CD44 (abDSerotec, USA), mouse 
anti-horse MHC class II (abDSerotec, USA) labeled with fluorescein isothiocyanate. During the analyzes 10,000 events were recorded, being considered positive the markers with expression greater than $2 \%$.

\section{Fibroblastic Colony-forming unit assay (CFU-F)}

The capacity and self-renewal efficiency of UC-MSCs was evaluated by the CFU-F assay, in triplicate, according to the methodology described by Mensing et al. (14) with modifications.

The UC-MSCs (second passage) were plated at a low density (approximately $220 \mathrm{cells} / \mathrm{cm}^{2}$ ) in six wells plates and the cultures were fixed and stained with $1 \%$ violet crystal in $100 \%$ methanol on day 5 . The stained colonies with more than 20 cells were classified as CFU-F and counted. The calculation of the efficiency was done using the following formula: CFU-F efficiency $=$ (CFU-F counted/cells originally plated) $\times 100$.

\section{Hematological and ultrasound examinations}

Hematological and ultrasound examinations were performed on the day of cell transplantation (D0) and at D2 and D7 after transplantation. Blood samples were collected for determination of hematocrit, red blood cell counting, hemoglobin, MCV, MCHC, total protein, RDW, platelets, leukocytes, segmented, lymphocytes, eosinophils, basophils, monocytes, and fibrinogen. The values of hematological variables were analyzed according to the reference values of Jain (15) and Meyer \& Harvey (16).

Sonographic examinations were performed with ultrasound equipment (Mylab 30- The Esaote Group, Italy) with microconvex transducer, frequency of $6.6 \mathrm{MHz}, 70 \sim$ $95 \%$ gain, depth of $7 \sim 8 \mathrm{~cm}$ and approximately $2.5 \sim 3.5$ $\mathrm{cm}$ of focus. Muscular tissue was examined by ultrasound on D0, D2 and D7 before the procedures at all times and during the transplantation for correct positioning of the needle.

\section{Cellular transplantation}

Cryopreserved UC-MSCs for transplantation were thawed 150 days after cryopreservation in a water bath at $37^{\circ} \mathrm{C}$ for 2 minutes. After centrifugation the cells were resuspended in culture medium and plated in $75 \mathrm{~cm}^{2}$ culture flasks. After cell confluence of at least $80 \%$, UC-MSCs were trypsinized and cell concentration and viability determined by Trypan Blue exclusion (0.4\%).

After sedation of animals with $10 \%$ xylazine $(0.5 \mathrm{mg} / \mathrm{kg}$, Konig, Buenos Aires, ARG) intravenously, cell transplantation (D0) was carried out in two points in the middle of the superficial gluteal muscle at right and left sides with guided by ultrasound to determine the location and depth of application. Three million MSCs were resuspended in $0.9 \mathrm{ml}$ of HBSS. For transplantation, the total volume was divided in 9 points (100 $\mu 1$ each), and injected using a $1 \mathrm{~mL}$ syringe with a $40 \times 1.2 \mathrm{~mm}$ needle. In two other regions of the same muscle (right and left) 0.9 $\mathrm{ml} \mathrm{HBSS}$ was also administered in 9 points for the evaluation of distention caused by the injection of liquid, serving as a control group. We emphasize that all transplants were conducted with UC-MSCs from a single donor previously characterized as above. The use of a single donor was conducted to avoid interference and variability in assessments proposed.

\section{Muscle biopsies}

Six biopsies were performed on each superficial gluteal muscle of every animal at different time points, as shown in Fig. 1. The first two biopsies were made 30 days before transplantation of MSCs (D-30), to check the integrity of muscular fibers and absence of inflammation at both sides. The remaining biopsies were performed after the treatment (one at MSCs implantation region and other at HBSS region). After 48 hours (D2) the biopsies were performed on the left side and after 7 days (D7) on the right side. Both at D2 and D7 the biopsies were performed on the same side to avoid the inflammation caused by the procedure.

The biopsies were performed according to Padilha et al. (17), using a Bergström $6.0(6 \mathrm{~mm})$ needle for the collection of a considerable tissue sample.

The animals were sedated with $10 \%$ xylazine and anesthetic block was made subcutaneously with approximately $3 \mathrm{ml}$ of $2 \%$ lidocaine without vasoconstrictor. After antisepsis, an incision of $1 \mathrm{~cm}$ reaching the skin, subcutaneous and muscle fascia was done and the biopsy needle was inserted. The muscle tissue fragments collected were washed with saline solution to terminate muscle contraction and covered by neutral talc in order to protect the muscle architecture during cryopreservation. Each sample was stored in a cryotube and frozen in liquid nitrogen, being stored at $-196^{\circ} \mathrm{C}$ at a proper cylinder.

All transplantations and biopsies were preceded by ultrasound examination in addition to blood sampling for hematological parameters. After biopsies animals were accompanied by clinical examination to verify the formation of abscess or increase of volume on the region of the incision.

\section{Histological evaluation}

A total of 36 frozen samples of muscle tissue were sub- 

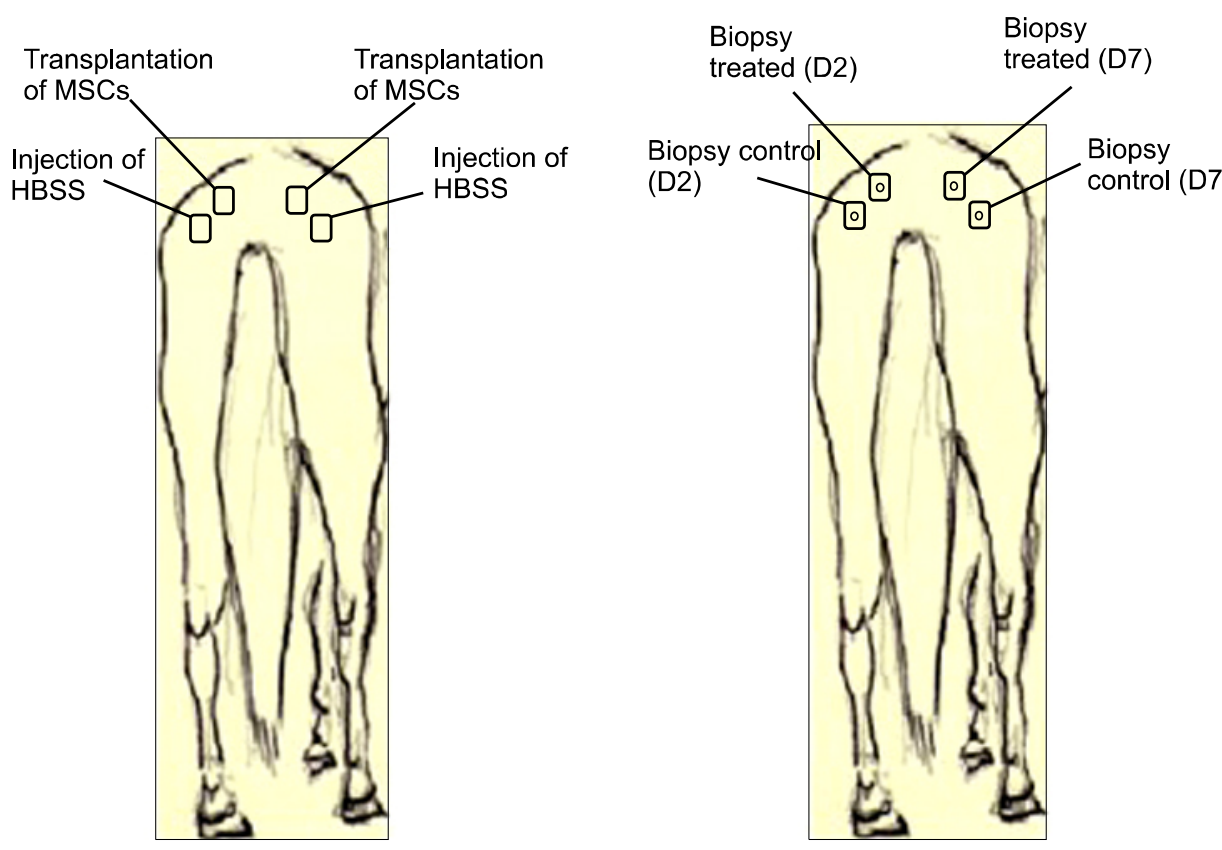

Fig. 1. Scheme of UC-MSCs transplantation and muscle biopsies. (A) Location of transplanting with UC-MSCs and HBBS. (B) Location of biopsies performed after transplantation (D2 on the left side and D7 on the right side).

Table 1. Graduation and criteria used for semi-quantitative analysis of the parameters in histology of superficial gluteal muscle of horses

\begin{tabular}{|c|c|c|c|c|}
\hline \multirow[b]{2}{*}{ Parameters } & \multicolumn{4}{|c|}{ Graduation } \\
\hline & $\begin{array}{l}\text { Degree } 0 \\
\text { Absent }\end{array}$ & $\begin{array}{l}\text { Degree } 1 \\
\text { Discreet }\end{array}$ & $\begin{array}{l}\text { Degree } 2 \\
\text { Moderate }\end{array}$ & $\begin{array}{l}\text { Degree } 3 \\
\text { Intense }\end{array}$ \\
\hline Neutrophilic infiltrate & Absent & $\begin{array}{l}1 \text { to } 10 \text { neutrophil by field } \\
(400 \times)\end{array}$ & $\begin{array}{l}11 \text { to } 20 \text { neutrophil by field } \\
(400 \times)\end{array}$ & $\begin{array}{l}>20 \text { neutrophil by field } \\
(400 \times)\end{array}$ \\
\hline Inflammatory infiltrate & Absent & $\begin{array}{l}\text { - Discrete inflammatory cells } \\
\text { - Focal distribution } \\
\text { - Only perivascular region }\end{array}$ & $\begin{array}{l}\text { - Multifocal distribution } \\
\text { - Perivascular regions and } \\
\text { interfascicular }\end{array}$ & $\begin{array}{l}\text { - Difuse distribution } \\
\text { - Interfascicular region }\end{array}$ \\
\hline $\begin{array}{l}\text { Degeneration/necrosis } \\
\text { of myocytes }\end{array}$ & Absent & 1 fiber by field $(100 \times)$ & 2 to 3 fiber by field $(100 \times)$ & $>$ fiber by field $(100 \times)$ \\
\hline
\end{tabular}

Adapted from Brasileiro et al. (18).

jected to histological processing in cross sections of $4 \mu \mathrm{m}$ thickness in a cryostat (Leica Microsystems, Wetzlar, Germany), extended onto glass slides and staining with hematoxylin and eosin (HE). For evaluation of histological parameters, the slides were observed in a light microscope (Axio Imager Al - Carl Zeiss, Oberkochen, GER) in a magnification of 100 to $400 \times$, coupled to a digital camera (AxiocamMRc - Carl Zeiss, Oberkochen, GER) and evaluated by Axiovision Software Rel. version 4.6 (Carl Zeiss, Oberkochen, GER). The qualitative morphological analysis included the evaluation of the presence and type of inflammatory infiltrate, neutrophilic infiltrate, degeneration/necrosis of fibers and presence or absence of fibrosis.

The semi-quantitative analysis was done based on the tissue components described above (with exception of fibrosis) and graduated as absent (grade 0), mild (grade 1), moderate (grade 2) and heavy (grade 3) as shown in Table 1. The values for neutrophil infiltration and degeneration/necrosis of myocytes were found by calculating the arithmetic mean of the number of cells counted in five fields per slide, similar to the methodology described by Brasileiro et al. (18). The evaluation of the degree of intensity of the inflammatory infiltrate was performed according to the pattern of distribution.

\section{Data analysis}

Data concerning hematological parameters were presented descriptively as mean and standard deviation, the CFU-F assay as mean and histological evaluation as median. Statistical analysis of hematological effect was done with the aid of the Sigma Plot software program for Windows version 11.0 (Systat Software, Inc., Erkrath, 
GER). Variables that did not pass the normality test (Kolmogov-Smirnov) were analyzed by One Way Repeated Measures Analysis of Variance. Tukey Test was used for all pairs of multiple comparison, adopting $\mathrm{p}<0.05$ as significant. For histological evaluation, the variables were analyzed using the Mann-Whitney test, adopting $\mathrm{p}<0.05$ as significant.

\section{Results}

\section{Collection, isolation and culture of UC-MSCs}

The use of umbilical cord for the isolation and culture of MSCs proved to be easy to obtain, without causing stress, pain and complications to the mare and foal. The isolation protocol was effective and a small portion of the sample was enough to obtain the desired cell concentration. The fibroblastoid morfology presented by
UC-MSCs was observed within 24 hours of culture and confluence of at least $80 \%$ on the seventh day of primary culture when subcultures were done.

\section{Potential to differentiate into mesodermal lineages}

The differentiation potential of UC-MSCs was demonstrated by the positive response to osteogenic and adipogenic differentiation. In osteogenic differentiation it could be observed the deposit of large amounts of extracellular matrix rich in calcium confirmed by the positive staining with Alizarim red. In adipogenic differentiation it could be observed the presence of large amounts of lipid droplets in the cytoplasm evidenced by positive staining with Oil red.

\section{Immunophenotypic profile and CFU-F}

Immunophenotypic analysis of UC-MSCs before and after cryopreservation revealed high expression of CD44
A

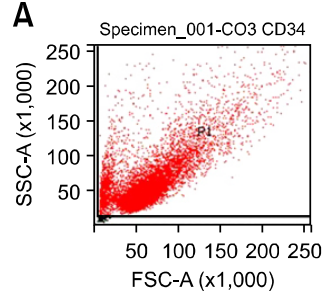

C

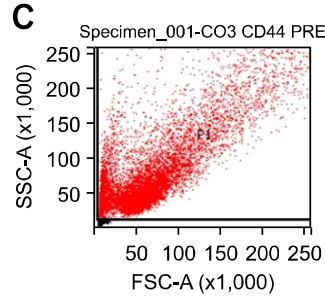

E

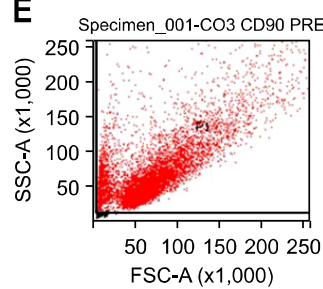

G

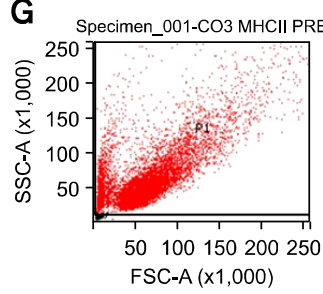

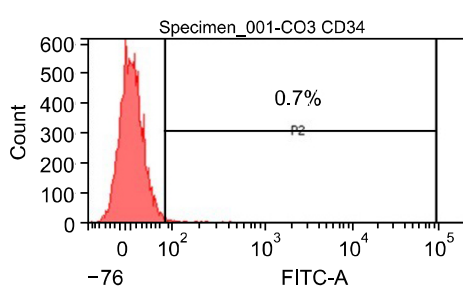
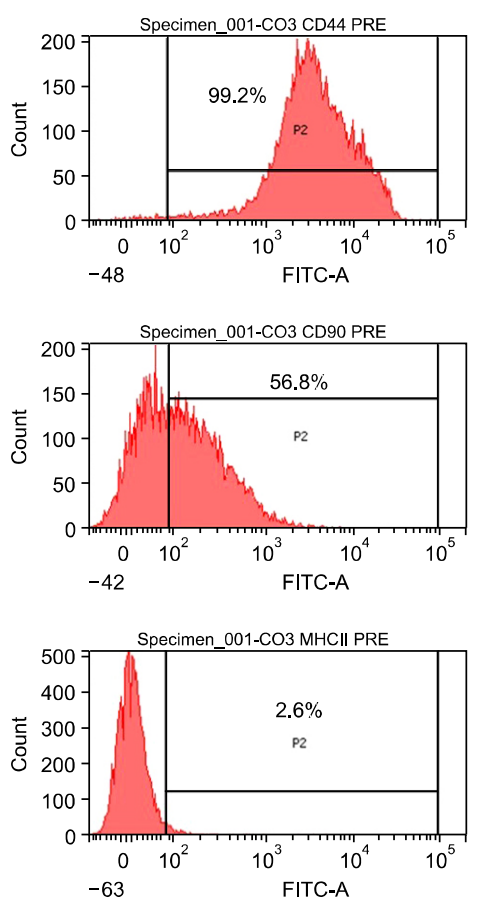

B
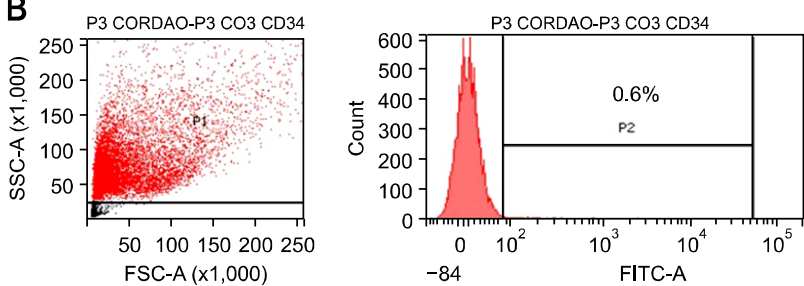

D
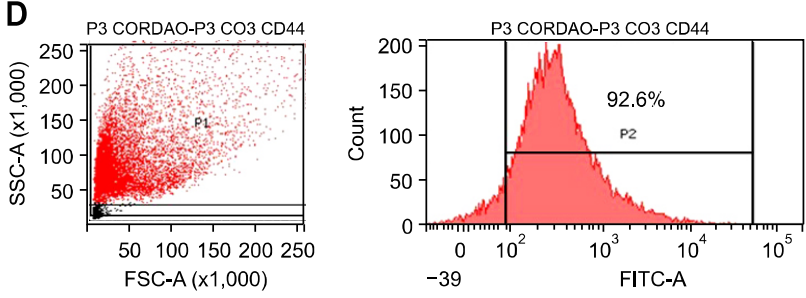

$\mathbf{F}$
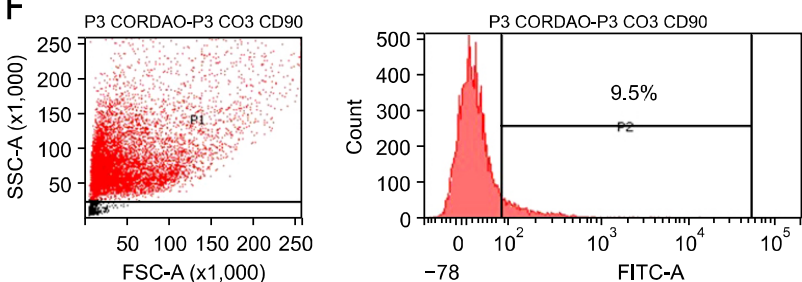

$\mathrm{H}$
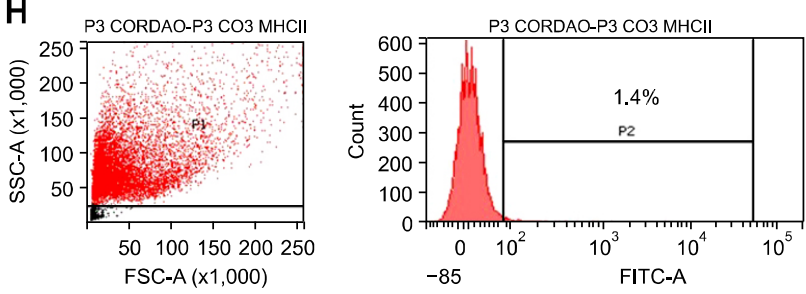

Fig. 2. Immunophenotypic analysis by flow cytometry of the markers CD34, CD44, CD90 and MHC-II of fresh UC- MSCs (A, C, E, G) and after cryopreservation (B, D, F, H). (A, B) Representative histograms of marker CD34 fresh (A) and after cryopreservation (B). (C, D) Representative histograms of marker CD44 (C) fresh and after cryopreservation (D). (E, F) Representative histograms of marker CD90 (E) fresh and after cryopreservation $(F) .(G, H)$ Representative histograms of marker MHCll $(G)$ fresh and after cryopreservation $(H)$. 
marker (99.2 and 92.6\% respectively) and negative or lower expression for MHC-II (2.6 and 1.4\%) and CD34 (0.7 and $0.60 \%$ respectively) as shown on Fig. 2. The average value for the number of colonies at CFU-F assay was 129 and the value of efficiency, $6.45 \%$. The test proved that the UC-MSCs have the ability to generate fibroblast colonies grown from single cells.

\section{UC-MSCs transplantation}

The cells transplanted were characterized immunphenotypically and presented optimal differentiation to mesodermal lineages, besides presenting fibroblastoid morphology and adhesion to plastic as described above. The average of viability of UC-MSCs transplanted after thawing in the six animals was $77.71 \%$.

The method chosen for the UC-MSCs transplantation was safe, did not cause infection and discomfort to the animal. It also provided a better distribution of MSCs in the demarcated region of muscle tissue.

\section{Hematological evaluation}

Hematologic variables (hematocrit, erythrocytes, hemoglobin, MCV, MCHC, total protein, RDW, platelets, leukocytes, segmented, lymphocytes, eosinophils, basophils, monocytes and fibrinogen) remained within the normal standard for equine species in all evaluations after transplantation of UC-MSCs, and differences $(p>0.05)$ were not observed for the variables studied between time points (D-30, D0, D2 and D7). The mean and standard error of the principal hematological parameters evaluated are shown in Table 2.

\section{Ultrasound examination}

Compared to the normal muscle observed in D0, the superficial gluteal muscle in D2 was heterogeneous, with the presence of hypo echogenic regions, with poorly defined and irregular borders in both groups (treated and control). The images generated at D2 suggested the presence of edema and possible inflammatory reactions related to injections performed on D0. At D7 the signals of edema were reduced and the hypo-echogenic regions observed previously diminished (Fig. 3) indicating resolution of inflammation. The image patterns observed were similar in the region that received MSCs or only HBSS, for both moments (D2 and D7).

\section{Muscle biopsies}

All biopsies were performed without difficulty and after the procedure, the animals showed normal behavior and no abscess or a volume increase was reported according to clinical examination.

\section{Histological evaluation}

Data about semi-quantitative evaluation of the tissue response to transplant of equine UC-MSCs in the superficial gluteal muscle are shown in Table 3. In the control group it was observed absence of mononuclear infiltrate (median $=$ 0 ) in all time points (D2 to D7) without difference ( $p>$ 0.05 ) when compared to treated group in which the median of the degree of mononuclear infiltration was 0.5 at D2 and at D7. The median intensity level in the histological evaluation of degeneration/myocyte necrosis was zero as well as for the parameter fibrosis, which was absent in all groups and moments. Differences $(p>0.05)$ between times points were not observed for any of the variables.

Comparing the time points it was observed difference $(p<0.05)$ only in neutrophil infiltrate between the time D-30 (right side - biopsy before treatment) and D2, in which median value of 0.2 (D-30) and 0.6 on treated group (D2).

Figs. 4 and 5 showed photomicrographs of histological

Table 2. Values of erythrocytes, hemoglobin, hematocrit, total plasma protein, leukocyte count, fibrinogen and platelets obtained from animals studied at all moments. Data are presented as mean and standard error

\begin{tabular}{lcccrrrr}
\hline Moment & $\begin{array}{c}\text { Erit } \\
\left(10^{6} / \mu \mathrm{L}\right)\end{array}$ & $\begin{array}{c}\mathrm{Hb} \\
(\mathrm{g} / \mathrm{dL})\end{array}$ & \multicolumn{1}{c}{$\begin{array}{c}\mathrm{Ht} \\
(\%)\end{array}$} & \multicolumn{1}{c}{$\begin{array}{c}\mathrm{TPP} \\
(\mathrm{g} / \mathrm{dL})\end{array}$} & $\begin{array}{c}\text { Leukocyte } \\
\left(\times 10^{3} / \mu \mathrm{L}\right)\end{array}$ & \multicolumn{1}{c}{$\begin{array}{c}\text { Fibrinogen } \\
(\mathrm{mg} / \mathrm{dL})\end{array}$} & \multicolumn{1}{c}{$\begin{array}{c}\text { Platelets } \\
(\mathrm{Plat} / \mu \mathrm{L})\end{array}$} \\
\hline D-30 & $6.8 \pm 0.23$ & $10.96 \pm 0.67$ & $31.6 \pm 1.47$ & $6.76 \pm 0.20$ & $8.23 \pm 0.67$ & $300 \pm 44.72$ & $185833 \pm 18481$ \\
D0 & $7.36 \pm 0.28$ & $12.36 \pm 0.49$ & $35.16 \pm 1.30$ & $7 \pm 0.19$ & $7.916 \pm 0.64$ & $366.66 \pm 33.33$ & $180033 \pm 12946$ \\
D2 & $7.56 \pm 0.14$ & $12.53 \pm 0.39$ & $34.66 \pm 0.84$ & $6.66 \pm 0.15$ & $8.16 \pm 0.62$ & $266.66 \pm 42.16$ & $182516 \pm 16376$ \\
D7 & $7.45 \pm 0.25$ & $12.48 \pm 0.44$ & $35.16 \pm 1.07$ & $6.7 \pm 0.08$ & $8.13 \pm 0.29$ & $240 \pm 36.51$ & $185833 \pm 8092$ \\
\hline
\end{tabular}

Erit: erythrocytes; $\mathrm{Hb}$ : hemoglobin; $\mathrm{Ht}$ : hematocrit; TPP: total plasma protein; Plat.: platelets.

D-30 $=30$ days before UC-MSCs transplantation; $\mathrm{D} 0=$ cell transplantation; D2 =48 hours after UC-MSCs transplantation; D7=seven days after UC-MSCs transplantation.

Differences $(p<0.05)$ between moments were not observed for any of the variables. 

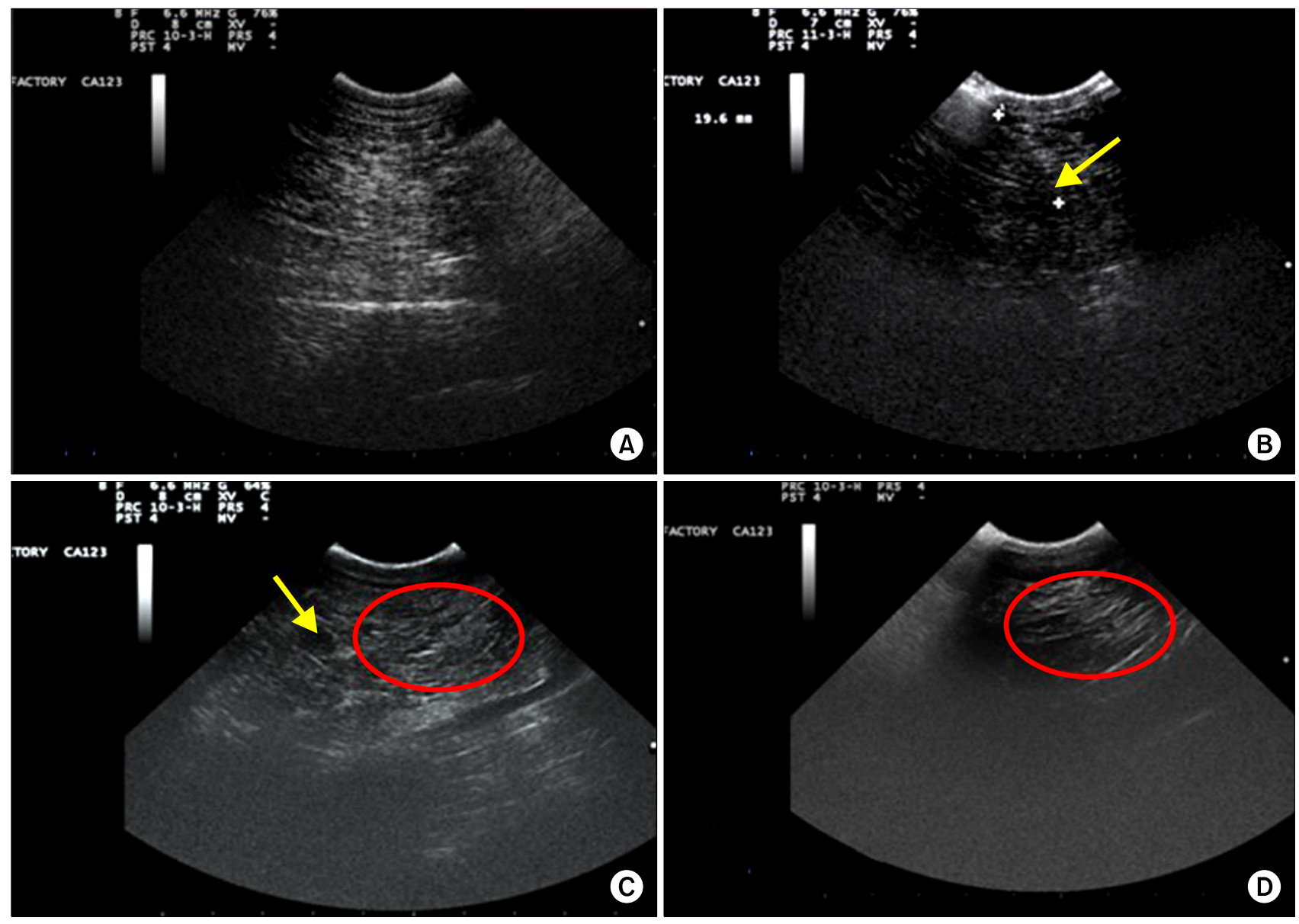

Fig. 3. Sonograms of equine superficial gluteal muscle at D0, D2 and D7 moments. (A) D0. Region that did not received UC-MSCs/HBSS injection. Note the arrangement of the muscle fibers of a healthy tissue. (B) Needle image (yellow arrow) being guided by ultrasound at a depth of about $2 \mathrm{~cm}$. (C) D2. Muscles with heterogeneous aspect (red ellipse) and presence of hypo echogenic regions (yellow arrow), after UC-MSCs injection. (D) D7. Improved aspect of the muscles with the presence of discrete hypoechoic regions permeated at the muscle fibers (red ellipse).

findings at all time points and groups. Muscle fibers preserved histologically were juxtaposed, each one surrounded by an endomysium (Fig. 4), arranged in fascicles delimited by perimysium (Fig. 4). Between this membranes blood capillaries (Fig. 4) were observed. In all 36 analyzed biopsies, inflammatory infiltrate was noticed in three biopsies from control group (one at D2 and two at D7) and in six biopsies from treated group (three on each moment). At D-30, six biopsies revealed discreet inflammatory process. The result of the histological analysis of the slides revealed degeneration and necrosis of the muscle fibers in only one field of four biopsies from the total of 36 analyzed. In addition, three were in the control group, one at D2 and two in D7, demonstrating that degeneration and necrosis fibers occurred even without the presence of UC-MSCs. Degeneration (Fig. 5) and necrosis (Fig. 5) of muscle fibers were indicated by the increase of sarcoplasmic eosinophilia and nuclear pyknosis were noticed. Moreover, the edema was represented by the increased space between damaged muscle fibers.

\section{Discussion}

In the present study equine UC-MSCs showed a positive expression of the markers CD44, CD90 as well as the absence or lower expression of the markers CD34 and MHCII in the moments studied. This feature is consistent with other studies conducted with various sources of MSCs in equine species (19-22). The reduction on CD90 expression after cryopreservation may be due a larger changes on the epitopes of this antigen after cryopreservation, once that the expression observed for the other markers remained similar in the moments studied. The absence or lower expression for the marker MHC-II at the 
Table 3. Results of semi-quantitative evaluation of the tissue response to transplant of equine UC-MSCs in the superficial gluteal muscle of horses

\begin{tabular}{|c|c|c|c|c|c|c|c|c|c|c|}
\hline \multirow{2}{*}{ Moment } & \multicolumn{2}{|c|}{ Neutophilic infiltrate } & \multicolumn{2}{|c|}{ Mononuclear infiltrate } & \multicolumn{2}{|c|}{$\begin{array}{l}\text { Degeneration/necrosis } \\
\text { of the myocytes }\end{array}$} & \multicolumn{2}{|c|}{ Fibrosis } & \multicolumn{2}{|c|}{$\begin{array}{l}\text { Immature muscle } \\
\text { fibers/Regenerated }\end{array}$} \\
\hline & $\begin{array}{c}\text { Left } \\
\text { muscle }\end{array}$ & $\begin{array}{c}\text { Righ } \\
\text { tmuscle }\end{array}$ & $\begin{array}{c}\text { Left } \\
\text { muscle }\end{array}$ & $\begin{array}{l}\text { Right } \\
\text { muscle }\end{array}$ & $\begin{array}{c}\text { Left } \\
\text { muscle }\end{array}$ & $\begin{array}{l}\text { Right } \\
\text { muscle }\end{array}$ & $\begin{array}{c}\text { Left } \\
\text { muscle }\end{array}$ & $\begin{array}{l}\text { Right } \\
\text { muscle }\end{array}$ & $\begin{array}{l}\text { Left } \\
\text { muscle }\end{array}$ & $\begin{array}{l}\text { Right } \\
\text { muscle }\end{array}$ \\
\hline \multirow[t]{2}{*}{ D-30 } & 0 & $0.2^{*}$ & 1 & 0 & 0 & 0 & 0 & 0 & 0 & 0 \\
\hline & Control & Treated & Control & Treated & Control & Treated & Control & Treated & Control & Treated \\
\hline D2 & 0 & $0.6^{*}$ & 0 & 0.5 & 0.16 & 0.16 & 0 & 0 & 0 & 0 \\
\hline D7 & 0.3 & 0.6 & 0 & 1 & 0.3 & 0 & 0 & 0 & 0 & 0 \\
\hline
\end{tabular}

Results are presented as median. Classification of intensity: Degree 0: Absent; Degree 1: Discreet; Degree 2: Moderate; Degree 3: Intense. Differences $(p<0.05)$ between the control and treated group were not observed for the variables between moments. $(*)$ Indicate significant differences in the same row. At the time point D-30, the expression left and right muscle indicates the two biopsies regions performed 30 days before treatment

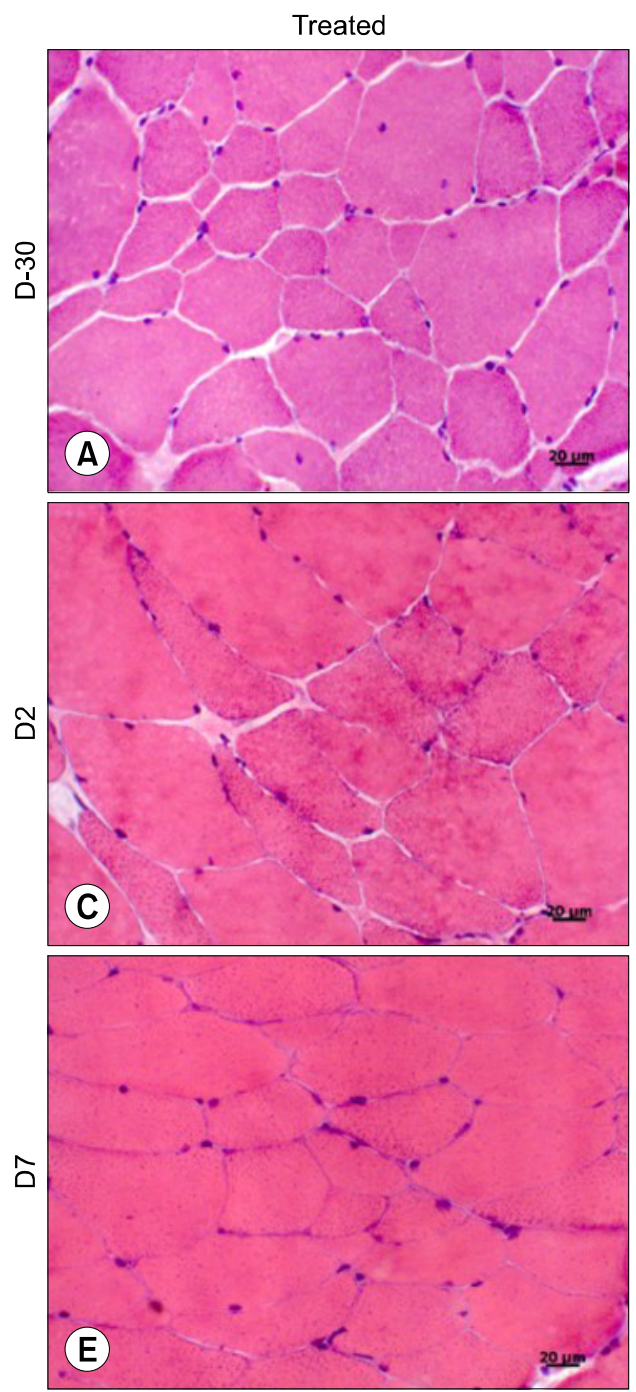

\section{Control}
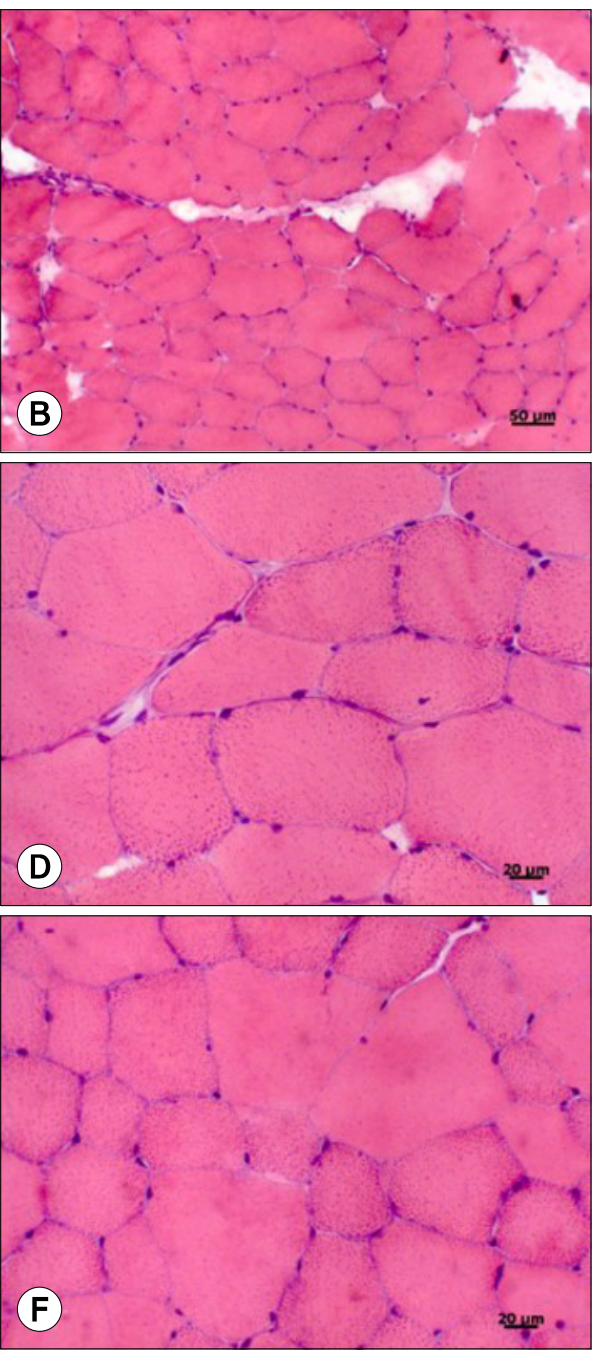

Fig. 4. Photomicrographs of biopsied superficial gluteal muscle without histological changes. (A, B) Moment D-30. (C) Moment D2, treated. (D) Moment D2, control. (E) Moment D7, treated. (F) Moment D7, control. end of the second culture and after cryopreservation obtained at our study differs from the results obtained by Schnabel et al. (23) with equine BM-MSCs in which the average values were higher (49.84\%). Additionally, the positive response to the osteogenic and adipogenic differentiation observed at our study was also reported by 

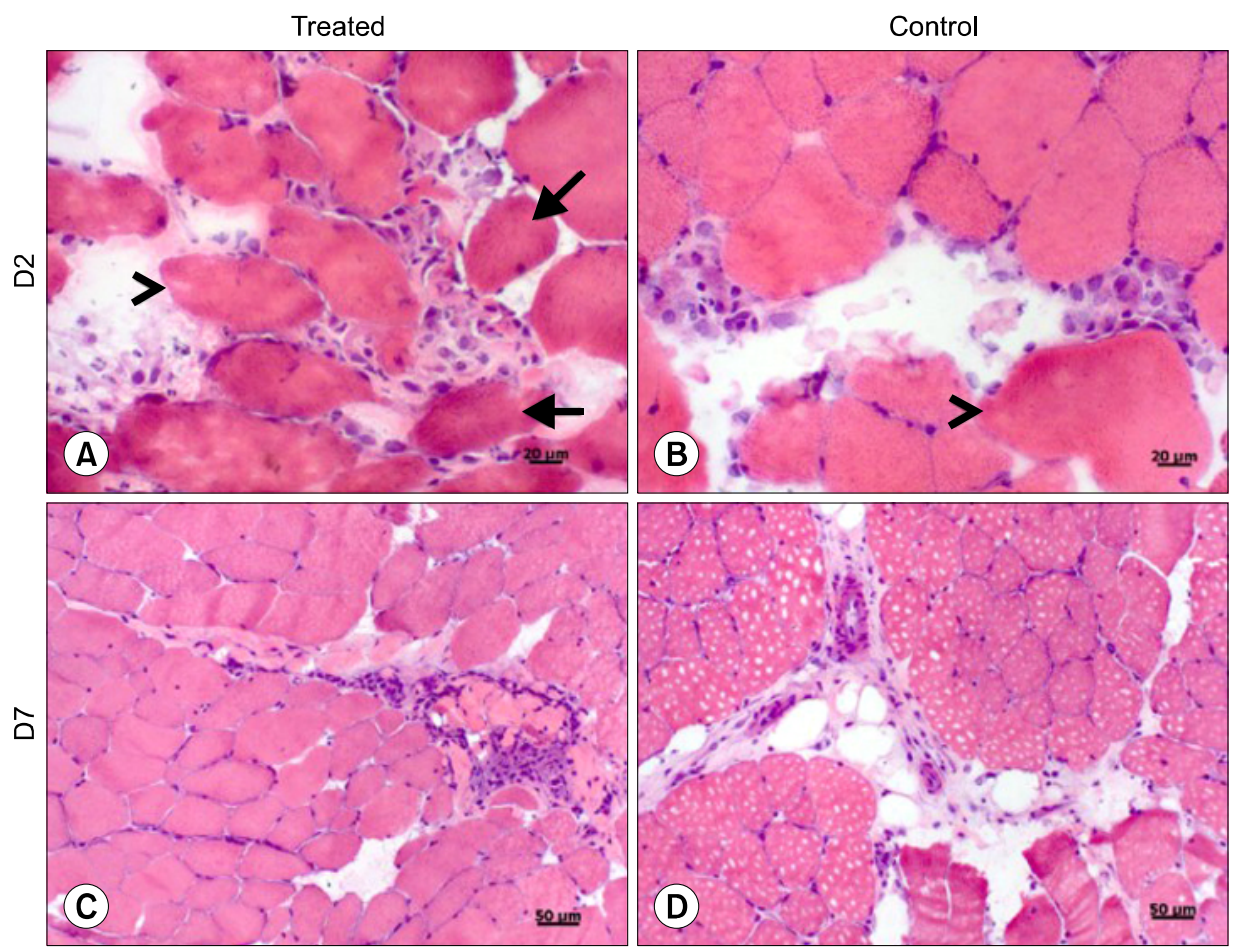

Fig. 5. Photomicrographs of superficial gluteal muscle biopsies with signals of mild inflammation. (A) Treated group at moment D2: Inflammatory infiltrate composed mostly of macrophages, and rare neutrophils. Degeneration (arrowhead) and necrosis (arrow) of muscle fibers indicated by the increase of sarcoplasmic eosinophilia and nuclear pyknosis were noticed. (B) Control group at moment D2: Interfascicular inflammatory infiltrate composed by macrophages and rare lymphocytes. Degenerated muscle fibers (arrowhead). (C) Treated group at moment D7: Inflammatory infiltrate involving the collagenous stroma (perimysium). (D) Control group at moment D7: Photomicrograph showing discrete perivascular inflammatory infiltrate composed by macrophages and discrete lymphocytes, associated with interfascicular edema.

Corradetti et al. (19) and Barberini et al. (24) also in UC-MSCs.

Hematological and ultrasound examinations were performed to complement and consolidate the low immunogenicity of UC-MSCs after transplantation. Muscle tissue is one of the softest tissues better adapted to ultrasonography and allows the evaluation of inflammation (25) demonstrated by an image in which muscle fibers become hyperechogenic and the presence of exudate turns the fibro-adipose septa on hypoechoic (26).

In our findings of ultrasound evaluation, the assessment made in D2 suggesting acute inflammation with resolution on D7 seems to be related to trauma (needle insertion and volume of liquid injected), since no difference was observed between the regions that received the UC-MSCs and the ones receiving only HBSS.

Hematological parameters are important in the analysis of safety in using allogeneic MSCs since it allows evaluation of leukocyte response, which results in alteration changes of the leucogram during acute inflammation. Our results showed that the application of horse UC-MSCs into muscle tissue in the conditions performed in this experiment did not incite systemic inflammatory response. In a recent work, Kol et al. (27) made multiple intravenous injections of allogeneic adipose-derived mesenchymal stem cells (AT-MSCs) and BM-MSCs. Clinical evaluation revealed no adverse signals and no effect in hematological parameters. However, the dosage of CD8+ cells by flow cytometry was increased in horses that received BM-MSCs transplantation, revealing a response without changes the clinical parameter considered normal. This did not occur with the animals that received AT-MSCs, indicating that the heterogeneity of BM-MSCs may induce small hematological changes.

The presence of a discreet inflammation on histological analysis after 48 hours from the application of UC-MSCs, with resolution by $\mathrm{D} 7$ is an expected found once it is common to observe inflammatory cells after transplantation of various cell types. In a study of horse intra-articular allogeneic BM-MSCs transplantation made by Pigott et al. (9) inflammatory reaction was observed 48 hours after application, but ceased in a range between 7 and 28 days spontaneously. The authors compared the allogeneic, genetically modified allogeneic and xenogeneic cells; and despite the degree of inflammation was higher in allogeneic and xenogeneic groups, in all the groups a certain degree of inflammation was observed, corresponding to the acute phase of injury.

In a similar study, Carrade et al. (19) injected intradermally MSCs from autologous and allogeneic UC and evaluated histologically the inflammatory process 48 hours, 72 hours and 7 days after application. Analysis showed a similarly tissue response between autologous and allogeneic MSCs injections, with a peak occurring 48 
hours after transplantation and a solution of the process at 7 days, indicating a self-limiting response.

In the experiment conducted by Gala et al. (28), the authors demonstrated the induction of inflammatory response with autologous BM-MSCs into muscle tissue of rats with the hypothesis that MSCs cultured in vitro undergo phenotypic changes during extracorporeal handling and become immunogenic. These published findings indicate that it is common the reaction of the body when any biological material is inserted into an animal, both by the presence of the material used as by the manipulation, mainly because it was not administered any anti-inflammatory on this type of procedure.

In our study, the inflammatory infiltrate was also observed in the control group, allowing us to conclude that factors other than the presence of UC-MSCs incited a mild response, such as multiple injections during application. The inflammatory infiltrate, when present, was mostly perivascular and focal, indicating that the tissue response was not severe and would be resolved independently, not blocking the therapeutic use of UC-MSCs.

With the results obtained in the present experiment it was possible to conclude that the application of equine UC-MSCs to the superficial gluteus muscle do not cause significant inflammation that curse on tissue injury or rejection by the host organism. Therefore, the use of these cells in the therapy for focal osteomuscular injuries seems to be safe with a good potential for clinical use. In addition, to our knowledge, since there are no studies evaluating the immunogenicity of equine UC-MSCs in muscle tissue in vivo, the results should contribute significantly to the development of new cell therapies in horses. We also highlight the possibility of extrapolating our results to other species, since the horse is an exemplary experimental model for studies of the musculoskeletal system.

\section{Acknowledgments}

To FAPESP for the scholarship (Proc.2013/01383-0).

\section{Potential conflict of interest}

The authors have no conflicting financial interest.

\section{References}

1. Voswinkel J, Francois S, Gorin NC, Chapel A. Gastro-intestinal autoimmunity: preclinical experiences and successful therapy of fistulizing bowel diseases and gut Graft versus host disease by mesenchymal stromal cells. Immunol Res 2013;56:241-248

2. Durando MM, Zarucco L, Schaer TP, Ross M, Reef VB.
Pneumopericardium in a horse secondary to sternal bone marrow aspiration. Equine Vet Educ 2010;18:75-79

3. Paterson YZ, Rash N, Garvican ER, Paillot R, Guest DJ. Equine mesenchymal stromal cells and embryo-derived stem cells are immune privileged in vitro. Stem Cell Res Ther 2014;5:90

4. Dyson SJ. Are mesenchymal progenitor cells set to revolutionise management of musculoskeletal injuries in the horse? Vet J 2013;197:533-534

5. Carrade DD, Affolter VK, Outerbridge CA, Watson JL, Galuppo LD, Buerchler S, Kumar V, Walker NJ, Borjesson DL. Intradermal injections of equine allogeneic umbilical cord-derived mesenchymal stem cells are well tolerated and do not elicit immediate or delayed hypersensitivity reactions. Cytotherapy 2011;13:1180-1192

6. Carrade DD, Owens SD, Galuppo LD, Vidal MA, Ferraro GL, Librach F, Buerchler S, Friedman MS, Walker NJ, Borjesson DL. Clinicopathologic findings following intra-articular injection of autologous and allogeneic placentally derived equine mesenchymal stem cells in horses. Cytotherapy 2011;13:419-430

7. Kode JA, Mukherjee S, Joglekar MV, Hardikar AA. Mesenchymal stem cells: immunobiology and role in immunomodulation and tissue regeneration. Cytotherapy 2009; 11:377-391

8. Sohni A, Verfaillie CM. Mesenchymal stem cells migration homing and tracking. Stem Cells Int 2013;2013:130763

9. Pigott JH, Ishihara A, Wellman ML, Russell DS, Bertone AL. Inflammatory effects of autologous, genetically modified autologous, allogeneic, and xenogeneic mesenchymal stem cells after intra-articular injection in horses. Vet Comp Orthop Traumatol 2013;26:453-460

10. Maia L, da Cruz Landim-Alvarenga F, Taffarel MO, de Moraes CN, Machado GF, Melo GD, Amorim RM. Feasibility and safety of intrathecal transplantation of autologous bone marrow mesenchymal stem cells in horses. BMC Vet Res 2015;11:63

11. Lovati AB, Corradetti B, Lange Consiglio A, Recordati C, Bonacina E, Bizzaro D, Cremonesi F. Comparison of equine bone marrow-, umbilical cord matrix and amniotic fluid-derived progenitor cells. Vet Res Commun 2011; 35:103-121

12. Smith RK, Garvican ER, Fortier LA. The current 'state of play' of regenerative medicine in horses: what the horse can tell the human. Regen Med 2014;9:673-685

13. Maia L, Landim-Alvarenga FC, Da Mota LS, De Assis Golim M, Laufer-Amorim R, De Vita B, Barberini DJ, Listoni AJ, De Moraes CN, Heckler MC, Amorim RM. Immunophenotypic, immunocytochemistry, ultrastructural, and cytogenetic characterization of mesenchymal stem cells from equine bone marrow. Microsc Res Tech 2013;76:618624

14. Mensing N, Gasse H, Hambruch N, Haeger JD, Pfarrer C, Staszyk C. Isolation and characterization of multipotent mesenchymal stromal cells from the gingiva and the periodontal ligament of the horse. BMC Vet Res 2011;7:42 
15. Jain NC. Essentials of veterinary hematology. Philadelphia: Lea \& Febiger; 1993. 417

16. Meyer DJ, Harvey JW. Veterinary laboratory medicine: interpretation \& diagnosis. 2nd ed. Philadelphia: Sauders; 2004. 351

17. Padilha FGF, Suma R, Amorim RM. Avaliação prática da biópsia muscular percutânea por agulha em equinos. Hora Vet 2008;28:29-32

18. Brasileiro JL, Fagundes DJ, Miiji LON, Oshima CTF, Teruya R, Marks G, Inouye CM, Santos MA. Isquemia e reperfusão de músculo sóleo de ratos sob ação da pentoxifilina. J Vasc Bras 2007;6:50-63

19. Corradetti B, Lange-Consiglio A, Barucca M, Cremonesi F, Bizzaro D. Size-sieved subpopulations of mesenchymal stem cells from intervascular and perivascular equine umbilical cord matrix. Cell Prolif 2011;44:330-342

20. Iacono E, Brunori L, Pirrone A, Pagliaro PP, Ricci F, Tazzari PL, Merlo B. Isolation, characterization and differentiation of mesenchymal stem cells from amniotic fluid, umbilical cord blood and Wharton's jelly in the horse. Reproduction 2012;143:455-468

21. De Schauwer C, Piepers S, Van de Walle GR, Demeyere K, Hoogewijs MK, Govaere JL, Braeckmans K, Van Soom A, Meyer E. In search for cross-reactivity to immunophenotype equine mesenchymal stromal cells by multicolor flow cytometry. Cytometry A 2012;81:312-323

22. Ranera B, Lyahyai J, Romero A, Vázquez FJ, Remacha AR, Bernal ML, Zaragoza P, Rodellar C, Martín-Burriel I. Immunophenotype and gene expression profiles of cell sur- face markers of mesenchymal stem cells derived from equine bone marrow and adipose tissue. Vet Immunol Immunopathol 2011;144:147-154

23. Schnabel LV, Pezzanite LM, Antczak DF, Felippe MJ, Fortier LA. Equine bone marrow-derived mesenchymal stromal cells are heterogeneous in MHC class II expression and capable of inciting an immune response in vitro. Stem Cell Res Ther 2014;5:13

24. Barberini DJ, Freitas NP, Magnoni MS, Maia L, Listoni AJ, Heckler MC, Sudano MJ, Golim MA, da Cruz Landim-Alvarenga F, Amorim RM. Equine mesenchymal stem cells from bone marrow, adipose tissue and umbilical cord: immunophenotypic characterization and differentiation potential. Stem Cell Res Ther 2014;5:25

25. Lew HL, Chen CP, Wang TG, Chew KT. Introduction to musculoskeletal diagnostic ultrasound: examination of the upper limb. Am J Phys Med Rehabil 2007;86:310-321

26. Peetrons P. Ultrasound of muscles. Eur Radiol 2002;12: 35-43

27. Kol A, Wood JA, Carrade Holt DD, Gillette JA, BohannonWorsley LK, Puchalski SM, Walker NJ, Clark KC, Watson $\mathrm{JL}$, Borjesson DL. Multiple intravenous injections of allogeneic equine mesenchymal stem cells do not induce a systemic inflammatory response but do alter lymphocyte subsets in healthy horses. Stem Cell Res Ther 2015;6:73

28. Gala K, Burdzińska A, Idziak M, Wilczek E, Pączek L. Transplantation of mesenchymal stem cells into the skeletal muscle induces cytokine generation. Cytokine 2013; 64:243-250 